\title{
The Liberal Arts College Library: Paradox or Panacea
}

\section{Robert D. Stueart}

The academic library in liberal arts institutions of the twenty-first century will be changed from what it is today. It is not yet clear how that transition will be managed. The library's role will, however, remain central to the teaching and research functions of the institution. The challenge is to develop the right collections and services to meet changing needs. A modestly endowed liberal arts library, confronted by rising expectations coupled with rising costs, need not resign itself to the status quo.

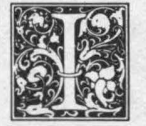

$\mathrm{n}$ recent years it has become much more difficult to define what is expected of academic libraries in liberal arts institutions. What is known is that there are varying opinions and attitudes. Some profess that libraries are not only the storehouses of knowledge, but also the primary purveyors of information that generates new knowledge. College administrators maintain that libraries gobble up inordinately high percentages of institutional budgets. Faculty, particularly those who received advanced degrees from large research institutions, express concern that the library is inadequate in research collection strength. Some mystics predict that "the book is dead" and therefore expenses and services could be curtailed. Many others observe that students seldom use libraries except as study halls. Such criticism sometimes breeds inertia, conservatism, and resignation. Most often, though, opinions reflect high expectations that remain unfulfilled. An oftquoted statement is that the library is the heart of the campus. But it may, in fact, be more like another organ, the liver, a large structure whose significance lies in a potential it may never be called upon to release. With those dynamics in place, then, what is the potential of the liberal arts institution's library-the collections, services, and use?

\section{FACULTY SUPPORT}

A major issue revolves around not only how, but also how much, faculty use college libraries. How aggressively do faculty encourage the use of libraries by students? Traditionally in the arts and sciences, faculty have required library use by their students. Further, sophisticated bibliographic instruction programs have been developed for undergraduate programs in many innovative institutions. But the notion of scholar librarian as teaching partner, even in those institutions with honors programs, has never really developed to its true potential.

One look at current faculty profiles reveals generations of faculty to whom it has not occurred that there is anything new to learn about libraries and their use. Some continue to rely on methods developed years ago, but these methods may no

Robert D. Stueart is Dean, Graduate School of Library and Information Science, Simmons College, Boston, MA 02115-5898. This article was originally presented as a Keynote paper at "The Past and Future of Liberal Education Conference" in Canada, April 29, 1989. 
longer be effective for research or even teaching purposes. ${ }^{1}$ In a classical " knowledge is power" approach to curricular content, the minds of students are treated like the livers of the Geese of Strasborgsundry bits are forced down. Some faculty who would never ask a librarian for help or advice, because such a request would be perceived as lack of knowledge or an admission of weakness, exacerbate the situation. At the other extreme, some faculty adamantly demand materials not in the collection and consistently insist upon research collections and outreach services that go beyond the individual library's capacities. A happy medium must define the role of the library to coincide with the mission of the larger liberal arts institution of which it is a part.

One requisite for all libraries is to initiate programs that effectively introduce all faculty to the resources and capabilities of libraries in liberal arts institutions. Limited resources and greater demands upon services have further pushed libraries in that direction. Libraries now aim for an approach that encourages faculty selfeducation about use and services. But this approach first requires libraries to find the tools, develop the techniques, and employ the technologies that enable the process to occur, while not losing sight of the unique needs and interests of individual faculty. This approach is perhaps a luxury not available to larger, more complex libraries. Inordinate amounts of time are spent developing teaching strategies, bibliographies, and marketing plans to include bibliographic instruction in the college curriculum so that students will know how to find information to become information literate. Faculty are often ignored in that process.

\section{RESEARCH}

Recognizing and reaching out to faculty as patrons may well be the greatest challenge facing academic librarians today. How can and should librarians develop faculty use, other than recognizing them as a group with specific characteristics, which may vary among the disciplines in which they work? Different institutional environments place varying professorial demands upon faculty to succeed-in teaching, in research, and in related professional activities.

\section{Recognizing and reaching out to fac- ulty as patrons may well be the great- est challenge facing academic librari- ans today.}

In some institutions research is frowned upon. The inference is that teachers who divert their energies toward research are strengthening their wings for flight to a higher level of recognition on a research university campus. This flight is perceived as being at the expense of the undergraduate liberal arts institution. In other instances, research receives grudging approval, though it is not demanded. In such institutions, researchers can set their own pace without deadline pressures and with time for reflection. Those faculty are likely to be the ones who appreciate the library most because they realize their research otherwise would be curtailed. Still other colleges expect faculty to extend the frontiers of learning and thereby bring to the classroom greater understanding. These are perhaps the ones most difficult for college libraries to serve because aspirations are toward research institution status and demands upon collections and services are inordinate. These scenarios each reflect different attitudes toward library service. Institutions where research does not occur are institutions where the library does not flourish. The question then becomes how much and to what depth libraries can support research interests in liberal arts colleges.

What has been called the "Research University Library Syndrome" has overtaken many good liberal arts institutions. This less-than-productive attitude causes faculty, administrators, and librarians to think of their libraries in terms of research libraries-and thus to imitate their practices, policies, and missions. ${ }^{2}$ This reaction is probably a natural one since "faculty are taught to perform research rather 
than to teach during their graduate training. ${ }^{\prime \prime 3}$ They have been trained as scholarresearchers and want to retain that in their career patterns.

Further, the syndrome has been promoted by librarians conditioned to buy more books, provide more services, and do a little bit of everything if it is requested. If college librarians are guilty of anything, it is trying to tailor services to specific needs of individuals being served. Unfortunately finances haven't kept pace with those rapid-fire agreements.

\section{What has been called the "Research University Library Syndrome" has overtaken many good liberal arts in- stitutions.}

Requirements for promotion and tenure in those liberal arts institutions vary from those in research institutions. But that line seems to be fading daily. In the past a resounding "yes" would have been shouted to whether there is a difference between liberal arts institutions and research universities. However, unscientific observation would indicate that the division is less clearly focused. Yet, the answer to that question determines, to an extent, the motivation of faculty to use the library for research purposes, to encourage students in their use, to take advantage of other creative outreach services and to participate in programs that librarians might try to implement for the faculty's benefit.

Interestingly, when faculty priorities are articulated, the most prevalent need by faculty seems to be in reserves, individual book purchasing, interlibrary loan or borrowing privileges, with less attention to how libraries are used or how they could effectively contribute to the learning process. Such lack of expectation would dictate a passive role, devoted to housekeeping, compiling bibliographies, and putting materials on reserve. Deans and presidents, most of whom come from faculty ranks, perpetuate that attitude.

\section{COLLECTIONS}

When library materials collection strengths are considered, some liberal arts colleges have pursued comprehensiveness, perceived as a "good thing," at the expense of depth. In other cases libraries have developed as storehouses for eclectic collections serving individual faculty members' research needs and, in the process, ignoring the basic teaching role of the college library. Acquisition of materials for faculty members is often made at the expense of materials that are less highly regarded by specialists but more appropriate for undergraduates. The result could be a fragmented collection, dotted with eccentric and obsolete books and journals unrelated to contemporary academic needs, and even worse, revealing embarrassing gaps in subject areas actively taught. ${ }^{4}$

Librarians are caught between the demands of tenured faculty for continued subscriptions to their favorite specialized journals and for monographic subject area purchases while new faculty in different specialties are being recruited to develop new avenues in the curriculum and to begin their own teaching and research careers. This presents an acute issue in the small competitive liberal arts college. ${ }^{5}$ It forces libraries to justify spending for research materials at the expense of the general collection, a phenomenon probably unique to liberal arts institutions.

\section{RESOURCE SHARING}

What then are the options and alternatives, with limited resources and budgets, and greater expectations and pressures? The materials ownership orientation must give way to a client use orientation, with the primary factor being accessibility. Debate now focuses increasingly on how much the institution should own as contrasted to how much it should access materials when they are needed. Obviously, a strong, immediately accessible collection has no substitute. That is primary to any liberal arts institution of quality. Supplementing that strong basic collection with resources outside the institution, however, is not only desirable but also manda- 
tory. Standards for academic libraries promote the concept of resource sharing, and libraries are less reluctant to abandon the notion of self-sufficiency. Even the larger research libraries can no longer possess a comprehensive range of resources sufficient to meet all patron needs, real or potential. This presents a problem of magnitude for libraries because it is a fact that most users, including faculty, search out only what is held locally and immediately available. Ways must be found to adjust the pattern and perception of need, use, ownership, and access.

Traditionally, the role of the library in a liberal arts institution has been in support of teaching by faculty and "search" rather than "research" by students.

The concept of resource sharing further brings into focus the demands of small liberal arts college libraries upon the larger research libraries that are themselves strained. Further, the cost of interlibrary loan is becoming unaffordable. The fax machine is an example of recent technological development that will enhance resource sharing. But before extensive networking and resource sharing is deemed the panacea, libraries must discover what needs are not being met by traditional collections and programs offered locally. A disproportionate percentage of the collection is never consulted. Resource sharing might allow librarians to be more selective and to eliminate duplications of materials, particularly those likely to receive infrequent use. Such a plan would permit indepth development of collections in certain subject areas. That quality aspect is particularly important for liberal arts institutions.

Traditionally, the role of the library in a liberal arts institution has been in support of teaching by faculty and "search" rather than "research" by students. The level of involvement has been passive or reactive. However, if libraries are to become proactive, both the service concept and its com- plementary budgeting support must be altered. If services to meet research needs of faculty are to be developed, a major shift in priorities and a new look at outreach services are required. The Association of College and Research Libraries projected output measures for academic libraries should provide guidance in addressing those issues.

\section{TECHNOLOGY}

Libraries must now search for ways to superimpose modern information services upon traditional functions while they make an orderly transition into the information age. Three areas of information technology-computing, communication, and content-have made dramatic changes in liberal arts college libraries. Multi-format collections available interinstitutionally reflect that trend. Online database searching and CD-ROM technology have sped up the bibliographic aspects. Special attention is now being paid to accessing the physical materials in all their formats-book, microform, video disk, film, or whatever. By the end of this century libraries will have made a major transition and will be fulfilling their traditional mission differently with the help of new technology. Librarians appreciate how difficult it is for anyone outside the profession to understand and keep up with rapid changes in technological application to library operations. In that regard librarians have gained new respect for themselves as professionals. For the first time, lack of proper technology is not the obstacle. The human barrier, the librarians themselves, are the weakest link and liberal arts institutions must remain committed to strengthening that link through effective recruiting programs and through encouraging continuing professional development.

The technological revolution has already brought about more changes in libraries than any force since the invention of printing. It will continue to change the nature and mission of libraries. Alvin Toffler admonishes that "the most basic raw material of all-and one that can never be exhausted-is information including 
imagination. With information as a source of knowledge becoming more important than ever before, the new civilization will restructure education and redefine scientific research. ${ }^{6}$

\section{The proliferation of information, as- sociated with the information age, makes possible a more assertive level of service.}

The president of EDUCOM recently stated that "one of the grand challenges for technology in the coming decade is to create an electronic network linking every scholar in the world to every other scholar and to establish a knowledge-management system on this world university network. The network will eliminate the isolation of scholars at small and remote institutions, encourage collaboration, speed up technology transfer, and enhance research productivity by reducing the time needed to obtain and exchange information. ${ }^{7}$ This future is a bright one.

\section{LIBRARY'S GENERAL ROLE}

"Every library" must be added to that equation. This addition would mean that libraries would be charged with making library resources available to an international network of scholars; libraries would develop a search-and-retrieval interface for those systems designed for the use of the scholars as well as other end-users. Individual institutions must recognize that they have an obligation to help researchers gain access to such networks as they develop.

The library's role will become enhanced rather than eliminated in that process. The role of the library will continue to change. Its services will be available in a much more decentralized fashion, and users may no longer have to go to a physical entity, "the library," to use its resources. This intangible aspect of library service emphasizes the concept of service rather than the physical building, and emphasis must be on staff as sources of information rather than on the library structure. Most importantly, the library will continue to play a vital role in selecting and disseminating information and to serve as an intermediary between the user in need of specific information and the sources of that information, in other words, to "add value."

\section{LIBRARY'S RESEARCH ROLE}

These technological applications have obviously enhanced the research role of liberal arts libraries. Research is becoming more a part of every faculty member's life. In the past faculty researchers' demands dictated passive and reactive levels of services. However, the proliferation of information, associated with the information age, makes possible a more assertive level of service. Efforts of faculty to remain current in their narrow fields of research-at the frontier of knowledge-will become increasingly difficult as scientific and technical knowledge accelerates. Staying current in the broader discipline, especially in those areas within the discipline that are not directly related to the faculty member's research or for which crossdiscipline or multidiscipline study has developed, will be an even greater challenge.

When a researcher is beginning to explore a new area of investigation, that person might logically turn to resources of the library. But oftentimes the search may center ort a review of citations used in related articles already owned by the researcher. Is that sufficient or is a more comprehensive approach desirable? The notion that a researcher identifies a problem and conducts a library literature search before extrapolating a hypothesis is not necessarily the way all researchers work. It is most likely that information found in the library is used to fill in the gaps or to bolster a point the author wishes to make rather than as the entry into an area. In short, literature may actually be as much a part of the writing or reporting process as the research process. This practice does not suggest that the library is less useful to the researcher, but it may suggest that use of the resources may 
come at a different stage in the researcher's enquiry. ${ }^{8}$

Different research practices mean that such services as the selective dissemination of information (SDI) and other current awareness services become more important. These services will become even more effective when offered via online information retrieval systems. For instance, a user profile of interest can be developed and citations of relevance to specific clientele then can be automatically retrieved and mailed periodically to the user. The emergence of electronic mail, local area networks, and other telecommunications technologies is making such services even more efficient. Current awareness services will become crucial concerns as libraries struggle with budget limitations and are forced to be increasingly selective in their purchases and user services. Further, research is a creative process that relies heavily upon the invisible college of scholars, and librarians as information managers can become a valuable link in this research partnership.

\section{SUMMARY}

It is clear that the academic library of the twenty-first century will be changed from what we know today, but it is not clear how that will be managed. What such a library must do in conjunction with its own clientele and funding authorities is to make a thorough reassessment of its service goals, one that takes into account both the actual mission of the institution and the environment in which it operates, and to develop objectives and implementation policies that stress the utility of books and other information media.

North American colleges were founded on the belief that the expansion of critical understanding and the development of individual autonomy are essential for a free and democratic society. The library's participation in the central mission of the liberal arts institution thus requires a commitment to reasoned inquiry, to the value of knowledge, and to the search for new knowledge that leads, hopefully, to wisdom. As the role of information increases on campuses, administrators and faculty are putting more pressure on libraries to respond. New demands result in the eclipse of priorities lower on the list. Today's libraries in liberal arts institutions are by their very nature in a state of overload, both in terms of information and in demand from the environment. They stand with one foot resting upon traditional values and services, with the other one raised toward the next century. The partnership of administrators, faculty, and librarians must make sure that the other foot is firmly placed on the higher ground that is rightfully the library's role in a liberal arts setting.

\section{REFERENCES AND NOTES}

1. Anne G. Lipow, "Teaching the Faculty to Use the Library," in New Horizons for Academic Libraries, ed. by Robert D. Stueart and Richard D. Johnson (New York: Saur, 1979), p. 262.

2. Evan Ira Faber, "College Libraries and the University Library Syndrome," in The Academic Library (Metuchen, N.J.: Scarecrow, 1974), p.14.

3. Edmund G. Harmann, "Access to Information," in New Horizons for Academic Libraries, p.535.

4. Ibid.

5. Tony Stankus, "Journal Weeding in Relation to Declining Faculty Member Publishing," Science and Technology Libraries 6:43 (Spring 1986).

6. Alvin Toffler, The Third Wave (New York: William Morrow \& Co., 1980), p.5.

7. Robert Grover and Martha L. Hale, "The Role of the Librarian in Faculty Research," College \& Research Libraries 49:10 (Jan. 1988). 


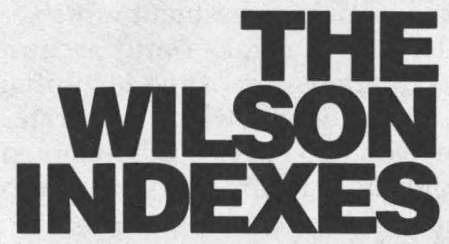

When You Need an Answer Fast and it Has to be Right

Offering broad coverage, unparalleled accuracy, and unmatched currency, the Wilson Indexes are your key to important literature in business and law, science and technology, art, education, the humanities, the social sciences, and general reference.

Now you can search these renowned indexes in print, online, on CD-ROM, and on tape.

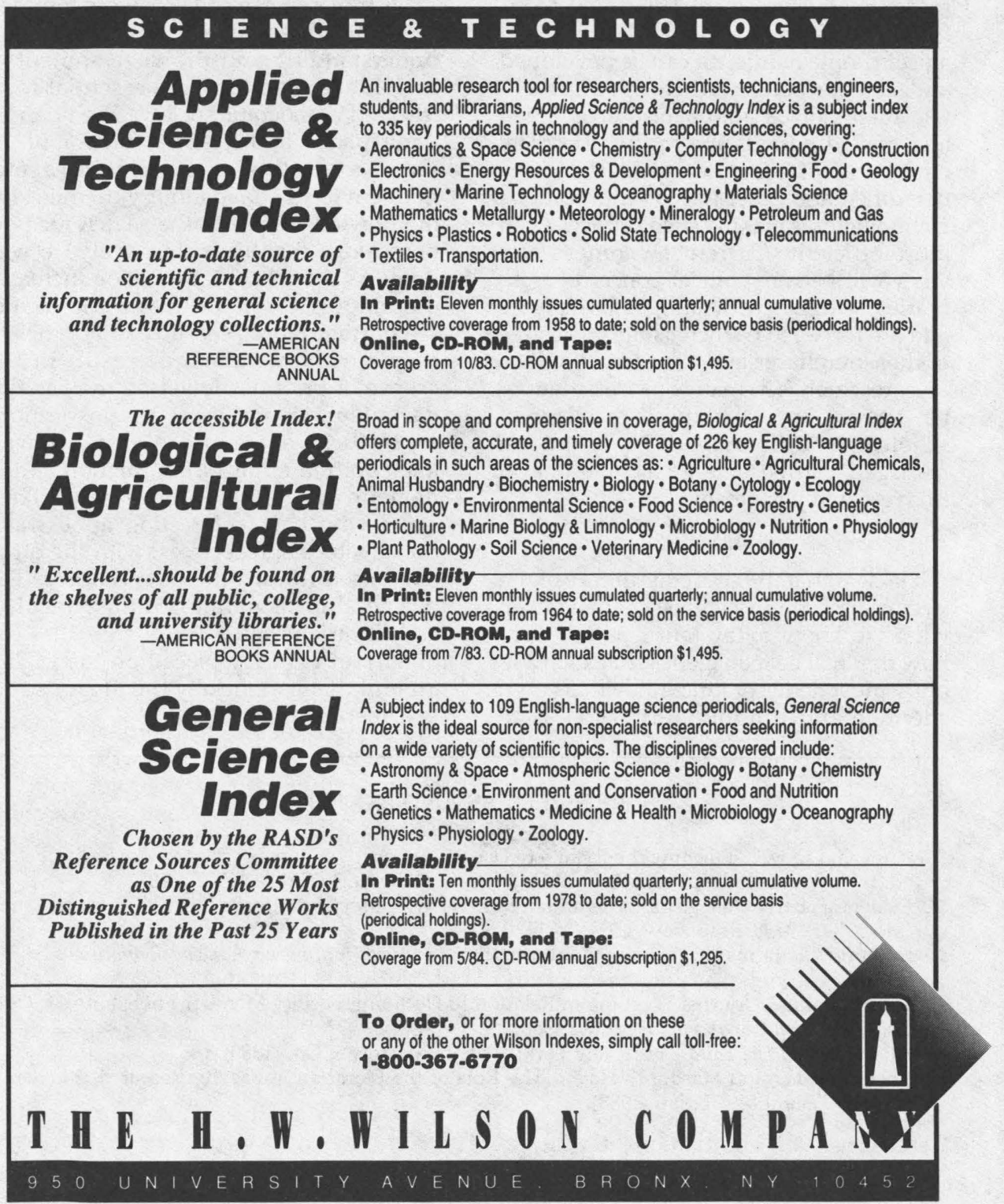

